\section{Free dental care for kids}

The University of Portsmouth's School of Professionals Complementary to Dentistry - a state-of-the-art training facility for dental nurses, hygienists and therapists - is working with Portsmouth City Council's Axcess Programme to provide free dental care to children from schools in Paulsgrove, a city ward where an estimated $70 \%$ of the population do not regularly visit a dentist.

Portsmouth children are almost half a tooth short of the national average when it comes to oral health, but the University of Portsmouth is helping to alleviate dental deprivation in the city by offering free dental check-ups and treatment to children from deprived sections of the community.

In the most recent clinic, the University provided a bus service for children and parents from Saxon Shore School in Paulsgrove. The children were seen by the school's dentists and student dental therapy assistants.

Meanwhile, the first intake of BSc Dental Hygiene and Therapy students has graduated from the University of Portsmouth. The 16 graduates began their course at the School of Professionals Complementary to Dentistry when it opened in 2004. The school cost $\mathfrak{E} 6.4$ million to establish and its facilities include a 24-bay treatment clinic, two private surgeries, a phantom head room, radiography suite and general teaching rooms. Three dentists are also employed full-time by the school and students do not have to pay tuition fees as they are fully funded by the NHS.

\section{Practice manager of 2007}

Sharon Holmes of Dental Arts Studio, London has won this year's Practice Manager Award presented by the British Dental Practice Managers' Association and 3M ESPE.

The award is judged on several criteria in a rigorous assessment procedure which includes a two-hour practice visit by a panel of judges and interviews with nominees and members of their practice.

Nominees are also required to provide clear evidence of how the practice manager has increased the success and profitability of the practice over the past few years in key areas including environment and procedures, team training and the patient journey. Four finalists were chosen from the greatest

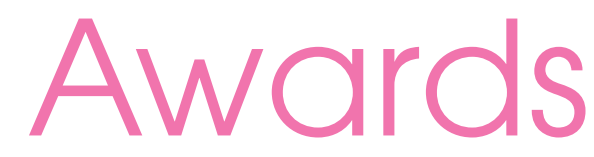

The El-Nashar Dental Care centre in Newton Abbot enjoyed success at this year's Dental Awards at the Royal Lancaster Hotel, London, by winning title of Best Dental Team Support winner as well as coming runner up in the Practice Manager of the Year category. number of nominations the award has ever received.

Chairman of the BDPMA, Bridget Crump, commented, 'In my five years as BDPMA Chairman, I have seen a definite trend from reactive manager to proactive leader, from administrator to strategist and from "just a title" to a pivotal practice role.'

The finalists were Marie Hobden of Surrenden Dental Practice, Brighton, Ellen Pattwell of The Queen Victoria Road Orthodontic Practice, High Wycombe, Kerry Zoina of Confident Dental Practice, Surrey and the 2007 winner, Sharon Holmes. Sharon was presented with a cheque for $\mathfrak{E} 500$ by $3 \mathrm{M}$ ESPE marketing manager Steve Foster.

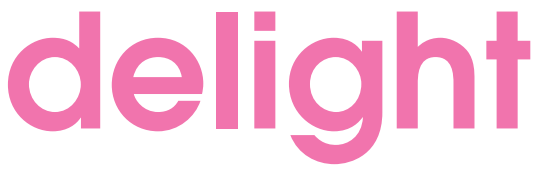

Jane Armitage of Sheffield practice, Thompson and Thomas, claimed the title of Practice Manager of the Year for the third year running. Jane is the first person in the history of the Dental Awards to have won the accolade of Practice Manager of the Year three times.

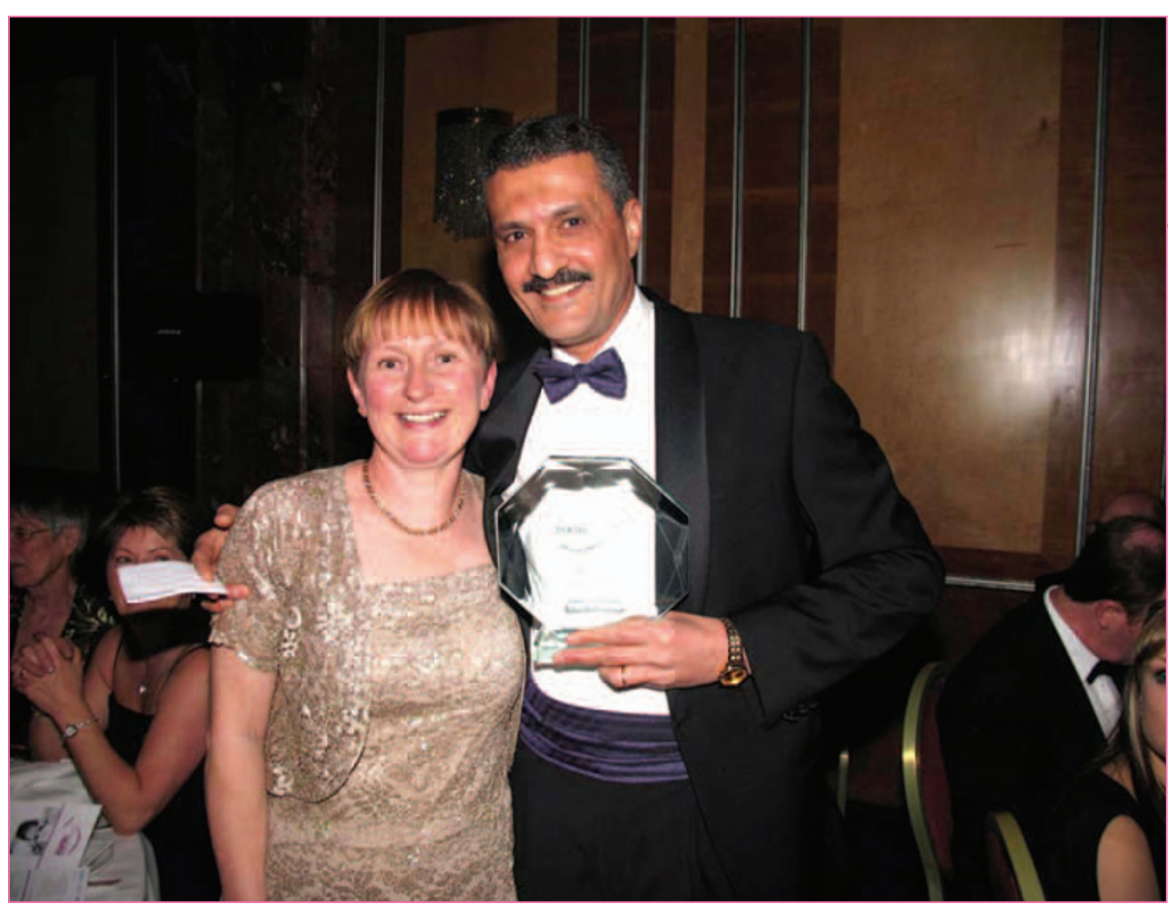

Sharon El-Nashar, Practice Manager and Hassan El-Nashar LDS RCS Eng, Principal 